\title{
O Livro de Provérbios no Novo Testamento: Um estudo de recepção e intertextualidade
}

\section{The Book of Proverbs in New Testament: A study of reception and intertextuality}

Marcelo da Silva Carneiro

\section{Resumo}

O estudo da Bíblia como produção literária tem sido bastante prolífico, tendo como uma de suas vertentes a intertextualidade e recepção dos textos. Nesse artigo será analisada a intertextualidade entre o Livro de Provérbios e os escritos do Novo Testamento, procurando perceber de que forma os autores utilizaram o livro sapiencial. Esse estudo faz parte de um processo maior, que analisa a relação do Novo Testamento com o Antigo. Como abordagem metodológica, adotaremos o método comparativo, para perceber tais usos, por meio de quadros sinóticos que ajudem a observar o fenômeno da intertextualidade. O Livro de Provérbios é um marco na literatura sapiencial pela sua diversidade de fontes e possibilidades de aplicação, e se tornou parte da rica tradição judaica para a humanidade. Como resultado, esperamos demonstrar que as comunidades cristãs primitivas tinham viva em sua memória os ensinamentos apreendidos pela tradição judaica, seja pela pessoa de Jesus e seu estilo sapiencial, seja pelos apóstolos, considerando uma espiritualidade sapiencial.

Palavras-chave: Intertextualidade. Livro de Provérbios. Recepção. Literatura Sapiencial. Novo Testamento. 


\begin{abstract}
The study of Bible as literary production has been quite prolific, having as one of its strands the intertextuality and reception of the texts. In this article, will be analyzed the intertextuality between the Book of Proverbs and the writings of the New Testament, looking for the way how the Authors used the wisdom book. This study is part of a larger process, that analyzes of the New Testament's relationship with the Old. As methodological approach, we use the comparative method, to realize such use, through synoptic frames that help to observe the phenomenon of intertextuality. The Book of Proverbs is a milestone in wisdom literature for its diversity of sources and application possibilities and became part of a rich Judaic tradition to humanity. As result, we hope show that the early Christian communities had a live memory of the Teachings from Judaic tradition, whether by the Jesus himself and his wisdom manner, whether by the apostles, considering a wisdom spirituality.
\end{abstract}

Keywords: Intertextuality. Book of Proverbs. Reception. Wisdom Literature. New Testament.

\title{
Introdução
}

Abordagens recentes da Bíblia como literatura tanto relacionam o texto bíblico com obras literárias da cultura ocidental, quanto analisam o texto bíblico como parte de uma rede textual intrincada e complexa. Neste artigo, iremos analisar o texto nesta segunda perspectiva, tendo como ponto de partida a forma como os autores do Novo Testamento fizeram uso, direto ou indireto, do Livro de Provérbios, importante fonte sapiencial para a cultura cristã.

Para realizar tal tarefa, serão observadas, por meio de comparação direta entre textos, a forma como os provérbios foram utilizados pelos cristãos que compuseram o material que gerou o Novo Testamento. A metodologia para tal comparação é feita, na maior parte das vezes, por meio de quadros sinóticos, que permitem a visualização rápida dos textos. Porém, a fim de que o artigo não se torne apenas um grande compilado de textos comparativos, fizemos uso de outros meios de comparação, às vezes por citação apenas do provérbio, ou, inversamente, do texto do NT. 
$\mathrm{Na}$ estrutura do artigo, haverá uma tentativa de estabelecer, logo de princípio, os conceitos de recepção e intertextualidade, a fim de que o leitor possa acompanhar apropriadamente a hipótese indicada. Além disso, será abordado, de modo geral, o uso do AT pelos cristãos, da forma como tem sido compreendida pelos pesquisadores. No segundo momento do artigo, analisarse-á o Livro de Provérbios propriamente dito, indicando aspectos históricos e literários que são importantes para compreender o papel desse material na mentalidade judaica e cristã nos séculos iniciais da era cristã. Numa terceira etapa, a maior do artigo, será feita a análise comparativa em si, buscando fazer as mais variadas relações, indicações de uso e significado dos Provérbios para os cristãos. Ao final, pretende-se sintetizar esse uso, indicando como Provérbios era compreendido pelas comunidades cristãs.

\section{Recepção e intertextualidade na produção bíblica}

Uma leitura atenta das Escrituras Sagradas demonstra a intensa relação literária entre os livros que a compõem. Isso tem relação direta com o uso dos materiais mais antigos e releituras feitas pelos próprios autores bíblicos. Ainda que o processo composicional de blocos literários como o Pentateuco ou os Profetas tenha sido longo, é possível perceber a influência dos diferentes materiais em literaturas posteriores. Essa relação tem sido entendida como um processo de recepção e intertextualidade na produção literária da Bíblia. Tais conceitos são importantes e devem ser devidamente expostos.

\subsection{Conceito de recepção e intertextualidade}

A transmissão dos escritos bíblicos gerou dois resultados: o natural processo de recepção dos textos e a subsequente intertextualidade. Apesar de estarem relacionados, cada um tem sua especificidade e pertinência. Paulo Augusto Nogueira, ao trabalhar a recepção como uma etapa hermenêutica, define a recepção "de forma dupla: como potencialidade do texto para releituras e como processo de apropriação e atualização do leitor distante no tempo" Assim, partimos da ideia de que todo texto, ao ser recebido, tornase objeto de hermenêutica e releitura de sua mensagem em novo contexto. A

${ }^{1}$ NOGUEIRA, P. A. S., Hermenêutica da Recepção, p. 17, destaques do autor. 
própria história do judaísmo comprova essa tese: a Mixná ${ }^{2}$ foi resultado de um longo processo interpretativo, a princípio oral, que depois se tornou material escrito, interpretando principalmente a Torá (Pentateuco).

Por sua vez, a intertextualidade é considerada uma noção instável, segundo a pesquisadora Tiphaine Samoyault, ${ }^{3}$ mas pode ser definida em termos gerais como o cruzamento de referências textuais em diferentes obras, onde os textos são utilizados de forma total ou parcial. Na intertextualidade está prevista ainda a alusão, que é uma citação por via indireta, em que um texto posterior faz releitura de textos anteriores, para uma nova situação. Evidentemente que, no ambiente oral dos textos bíblicos, essa intertextualidade não devia ocorrer apenas no campo escrito, mas principalmente pela tradição oral. Por isso, é muito natural que partes de materiais do Antigo Testamento tenham sido utilizadas de forma aleatória e até imprecisa pelos autores do Novo Testamento.

\subsection{O uso do AT pelos cristãos}

O estudo sobre a forma como os cristãos iniciais trabalharam com o Antigo Testamento está diretamente relacionado a um fato: a "Bíblia" que eles usavam, tanto Jesus como os apóstolos, era o Pentateuco e os demais livros que hoje formam o Novo Testamento. Ainda não havia um cânon judaico preciso ${ }^{4}$ mas certamente a maioria dos livros era bastante conhecida e lida pelas comunidades.

Tendo como ponto de partida esse fato, é possível verificar que as comunidades cristãs iniciais interpretaram o Antigo Testamento à luz do evento Jesus, que, por sua vez, interpretou a Lei e os Profetas sob uma ótica nova, pensando na expressão máxima da vontade de Deus. ${ }^{5} \mathrm{Na}$ verdade, só é possível

\footnotetext{
${ }^{2}$ A Mixná é uma palavra que em hebraico significa "repetir", e passou a designar algo ensinado ou estudado por repetição. No sentido da obra literária, "é o conjunto da Lei oral e de seu estudo, que é essencialmente caso de memorização e de recapitulação. Nesse sentido, mishnah (sic) contrasta com miqra (de quara, ler), que designa a Bíblia, a lei escrita, que se estuda e transmite pela leitura, uma vez consignada em livro". LENHARDT, P.; COLLIN, M., A Torah oral dos fariseus, p. 146. Esse material gerou uma coletânea, colecionada de 70 a 220 d.C., sendo a mais antiga literatura rabínica registrada.

${ }^{3}$ SAMOYAULT, T., A Intertextualidade, p. 13-14.

${ }^{4}$ Sobre essa discussão, ver BARRERA, J. T., A Bíblia Judaica e a Bíblia Cristã.

${ }^{5}$ A respeito disso, ver a comunicação: CARNEIRO, M. S., Jesus, a Torá e os Nebîim, e o pleno cumprimento da justiça em Mt 5,17-20.
} 
compreender o Novo Testamento quando se conhece, ao menos de uma forma geral, o Antigo. Como afirma David J. Ellis: "é axiomático o fato de que o NT depende grandemente do AT para a sua compreensão apropriada e que os livros do AT apontam para os do NT para seu cumprimento definitivo, não só no âmbito prescrito da profecia, mas também em toda a sua missão e mensagem". ${ }^{6}$

Há, de um modo geral, duas maneiras de citação do AT no NT: citações diretas, onde o texto é citado em sua íntegra, muitas vezes antecedido por fórmulas de cumprimento, como "pois está escrito" etc.; citações indiretas, ou alusões, quando o texto evoca uma passagem, sem utilizar as palavras exatas do texto utilizado como base. ${ }^{7}$

Evidentemente que, diante dessa situação, a maior parte das vezes em que o AT foi citado ou mencionado de forma indireta pelos autores do NT, houve uma clara hermenêutica cristã sobre os textos. Ellis indica alguns princípios de interpretação do AT utilizados pelos autores do NT: os cristãos tinham uma visão escatológica de mundo, pensando na iminente vinda do Senhor, logo, textos que apontam para a consumação, o juízo de Deus e outros aspectos similares, tinham preferência. Da parte de Jesus, o foco estava no processo de cumprimento (Mt 5,21), considerando que nele as profecias eram realizadas, ou ainda, que ele as atualizava em seu ministério (Lc 4,16-21). Essa ideia foi aprofundada pelos evangelistas e demais apóstolos, por isso o evento Jesus passou a ser analisado sob a perspectiva de cumprimento do AT. Ellis denomina esse processo como o uso de "testemunhas de pedra". ${ }^{8}$ Houve também uma utilização hermenêutica apologética, profética, alegórica e tipológica do AT, especialmente nos escritos paulinos, que associavam as histórias tradicionais com Cristo e a nova perspectiva sobre a salvação pela fé (Gl 4,21-31 e Rm 4,1-22). ${ }^{9}$

Além do uso dos textos do AT relacionados a Cristo, há também o uso por parte das comunidades cristãs relacionado aos próprios ensinamentos do AT, que eram apreciados pelos seguidores de Jesus e as comunidades cristãs iniciais. Isso é fruto natural da formação daquelas comunidades ser originada no ambiente judaico, antes delas aderirem à fé em Jesus. Aqui entra, de forma mais específica, a relação do NT com o Livro de Provérbios, o qual analisaremos a seguir.

\footnotetext{
${ }^{6}$ ELLIS, D. J., O uso neotestamentário do Antigo Testamento, p. 1538.

${ }^{7}$ MELGARES, J., Uso del Antiguo Testamento en el Nuevo, p. 47-51.

${ }^{8}$ ELLIS, D. J., O uso neotestamentário do Antigo Testamento, p. 1540-1543.

${ }^{9}$ MELGARES, J., Uso del Antiguo Testamento en el Nuevo, p. 61-62.
} 


\section{O livro de Provérbios como testemunho da sabedoria popular israelita}

A origem de Provérbios é considerada bastante complexa e tem sido fonte de diversas análises na pesquisa. Já na década de 1940, Cullen Story defendia uma origem no mundo semita do nordeste do Oriente Médio, comparando a métrica ugarítica com a do Livro de Provérbios, bem como as imagens utilizadas no livro hebraico. ${ }^{10}$ Por outro lado, mais recentemente, Ludger Schwierhorst-Schönberger comenta que "discute-se de forma controvertida a pergunta se a sabedoria proverbial de Israel cresceu a partir da sabedoria popular oral [...] ou se descende do círculo de professores sábios na escola e/ou de funcionários na corte real". ${ }^{11}$ Ele ainda aponta a relação entre os provérbios israelitas e africanos, ainda que em certo nível elementar, relacionado ao cotidiano. Sobre isso, comenta: "os ditados das áreas temáticas Deus e ser humano, os fiéis e os ímpios, que faltam entre os provérbios africanos, parecem ser já o resultado de uma reflexão teológica típica para Israel, sobre a sabedoria". ${ }^{12}$

Para Tewoldemedhin Habtu, de forma mais ampla, pode-se associar a literatura sapiencial israelita a textos do Antigo Oriente Médio, como o manual egípcio intitulado Ensinos de Amene-mope, a partir do qual se pode estudar esse material como um estilo literário específico dentro do cânon do Antigo Testamento. ${ }^{13}$ De uma forma mais direta e simples, Sylvia Villac e Donizete Scardelai afirmam o seguinte, a respeito desse material:

O povo de Deus também tinha os seus provérbios, muitos dos quais receberam a influência dos povos e das culturas vizinhas. O livro dos Provérbios é o mais típico da cultura sapiencial de Israel. Suas partes antigas não apresentam senão preceitos de sabedoria humana. As observações sobre a natureza e sobre os homens e mulheres, acumuladas de geração em geração, exprimiram-se em ditos populares e sentenças, que tinham uma aplicação moral e serviam de normas de conduta, que

\footnotetext{
${ }^{10}$ STORY, C. I. K., The Book of Proverbs and Northwest Semitic Literature, p. 319-329.

${ }^{11}$ SCHWIENHORST-SCHÖNBERGER, L., O Livro de Provérbios, p. 326-327.

${ }^{12}$ SCHWIENHORST-SCHÖNBERGER, L., O Livro dos Provérbios, p. 327.

${ }^{13}$ HABTU, T., Introdução à Literatura Sapiencial, p. 1517. Pode-se questionar a indicação de escritos egípcios como sendo do Oriente Médio, em vez da África, especialmente quando o comentador é um africano. Porém, não é o foco de nossa pesquisa nesse artigo, por isso não aprofundaremos a questão.
} 
apareceram desde os livros de $\mathrm{Sm}, \mathrm{Jz}$, Rs e até dos profetas, mas que têm sua condensação máxima no livro de Provérbios. ${ }^{14}$

Essas explicações nos mostram que, não importa a origem específica, o fato é que o Livro de Provérbios reverbera a sabedoria cotidiana da comunidade israelita, que se entendia como povo de Deus e vivia sob a fé a partir da aliança de Moisés. Neste sentido, Provérbios é o testemunho fixado da sabedoria vivenciada por esse povo. Ao ler o livro, pode-se perceber alguns tipos de testemunho: a sabedoria popular, fruto da oralidade cotidiana (Pr 10-15); o ensinamento formal, proveniente de escolas a partir de mestres da sabedoria (Pr 1-9); a sabedoria oficial, advinda do ambiente do palácio $(22,17-23,12)$; a sabedoria teológica, como fruto da reflexão sapiencial escrita (Pr 30). ${ }^{15} \mathrm{Na}$ composição do livro, em vários momentos esses tipos são entrelaçados e formam um conjunto misto, mostrando que, para os editores da versão canônica, as diferentes origens da sabedoria não importavam, mas sua mensagem e a formação moral do povo de Deus. Jean-Louis Ska chega a uma conclusão bastante peculiar: "Este provérbio [Pr 30,18-19] é muito parecido com os kōan da espiritualidade zen, ou seja, formulações enigmáticas que têm por objetivo provocar a reflexão". ${ }^{16}$

Tudo isso demonstra a amplitude com que a sabedoria proverbial tinha nas camadas populares do povo, tendo em vista que, até os nossos dias, provérbios e ditados são parte inerente do conhecimento popular sobre a vida. Ao mesmo tempo, o material sapiencial que foi preservado e depois canonizado por judeus e cristãos demonstra como outros grupos sociais, como os mestres da corte e até mesmo os sacerdotes, se utilizaram da sabedoria proverbial, desenvolvendo a teologia sapiencial $(\operatorname{Pr} 8)$.

Estabelecendo, então, uma correlação sobre o amplo uso de Provérbios entre os grupos judaicos, e dentre eles os movimentos de fé em Jesus, ${ }^{17}$ podemos ter como base o senso geral do uso do AT por estes, já apresentado.

\footnotetext{
${ }^{14}$ SCARDELAI, D.; VILLAC, S., Introdução ao Primeiro Testamento, p. 190.

${ }^{15}$ SCHWIENHORST-SCHÖNBERGER, L., O Livro de Provérbios, p. 327-328.

${ }^{16}$ SKA, J. L., O Antigo Testamento, p. 115.

${ }^{17}$ De acordo com Joachim Jeremias, o próprio Jesus incorporou essa linguagem, pelo fato de ensinar em aramaico, conforme o estudo dos seus ditos pode indicar. Ele afirma: "As palavras de Jesus transmitidas pelos sinóticos apresentam-se na roupagem de um grego coiné de traços semíticos". JEREMIAS, J., Teologia do Novo Testamento, p. 32. Jeremias ainda afirma que isso indica a forte relação linguística de Jesus com o mundo judaico, pois tanto o Talmude quanto os midrashim originários da Galileia atestam o aramaico como língua de comentário às Escrituras.
} 
Assim, podemos pensar, de forma bastante convicta, que essa obra fazia parte da vida das comunidades cristãs iniciais, tanto quanto os salmos ou os textos proféticos. Sabe-se que, no século 1 d.C. esse material ainda não tinha plena posição no cânon, tanto judaico quanto cristão, mas certamente gozava de grande prestígio junto aos dois grupos. Cabe agora, de uma forma mais direta, indicar o uso do Livro de Provérbios no NT, que pode nos dar uma ideia de como eles enxergavam essa obra.

\section{Citações de Provérbios entre os autores do NT}

Uma visão geral do uso de Provérbios no NT poderá nos auxiliar na percepção da relação dos autores com a obra sapiencial. Abaixo a relação de intertextualidade para uma visão panorâmica: ${ }^{18}$

\begin{tabular}{|l|l|}
\hline Mateus & $5,7=14,21(A), 17,5(A) ; 5,9=10,10(A) ; 5,39=20,22(A), 24,29(A) ; 5,44$ \\
& $=24,17(A), 25,21(A) ; 6,11=3,28(A), 27,1(A), 30,8(A) ; 7,7=8,17(A) ;$ \\
& $9,13=16,7(A), 21,3(A) ; 11,19=23,20(A) ; 11,29=16,19(A) ; 13,12=9,9$ \\
& $(A) ; 13,44=1,4(A) ; 13,46=3,15(A), 8,11(A) ; 15,23=31.6 \mathrm{~s}(A) ; 15,55=$ \\
& $28,24(A) ; 16,27=24,12(C) ; 21,32=8,20(A), 12,28(A), 21,21(A) ; 22,3=$ \\
& $9,3-6(A) ; 22,4=9,2.5(A) ; 23,12=29,23(A) ; 23,35=6,17(A) ; 25,8=13,9$ \\
& $(A) ; 25,40=19,17(A)$ \\
\hline Marcos & $7,11=28,24(A)$ \\
\hline Lucas & $1,30=12,2(A) ; 1,51-52=3,34(A) ; 2,52=3,3 \mathrm{~s}(A) ; 6,27=25,21(A) ; 7,34=$ \\
& $23,19 \mathrm{~s}(A) ; 7,35=8,32 \mathrm{~s}(A) ; 8,18=1,5(A), 9,9(A) ; 14,8=25,6 \mathrm{~s}(A) ; 15,13$ \\
& $=29,3(A) ; 16,15=24,12(A) ; 16,19=31,22(A) ; 23,31=11,31(A)$ \\
\hline João & $1,1=8,22-26(A) ; 3,13=30,4(A) ; 7,34=1,16(A) ; 7,38=18,4(A) ; 9,31=$ \\
& $15,8(A), 15,29(A) ; 14,23=8,17(A) ; 17,12=24,22(A)$ \\
\hline Atos & $1,26=16,33(A) ; 6,13=14,5(A) ; 13,10=10,9(A) ; 24,5=22,10(A), 29,8$ \\
& $(A) ; 24,16=3,4(A)$ \\
\hline Romanos & $2,6=24,12(C) ; 3,15=1,16(C) ; 9,31=15,9(A) ; 10,6=30,4(A) ; 12,16=3,7$ \\
& $(A) ; 12,17=3,4(A), 20,22(A) ; 12,20=25,21 \mathrm{~s}(C) ; 13,1=8,15 \mathrm{~s}(A)$ \\
\hline 1 Corintios & $2,10=20,27(A) ; 4,10=3,7(A) ; 4,13=21,18(A) ; 14,23=6,8(A)$ \\
\hline
\end{tabular}

\footnotetext{
${ }^{18}$ Seguindo as indicações de NESTLE, E.; ALAND, K., Novum Testamentum Graece, p. 856. Aqui invertemos a forma de organizar a relação, para evidenciar a quantidade de citações de $\mathrm{Pr}$ em cada livro do NT. Na organização da lista, a fórmula utilizada será: Mateus 5,7 =14,21 (A). Na primeira coluna o livro, na segunda a referência deste livro do NT, seguida da referência citada de Provérbios, seguida pelo $\mathrm{C}$ ou A entre parênteses, para indicar se é citação direta (C) ou alusão (A). Neste caso, Mt 5,7 faz uma alusão a Pr 14,21.
} 


\begin{tabular}{|c|c|}
\hline 2 Corintios & $\begin{array}{l}3,3=7,3(A) ; 8,21=3,4(A) ; 9,6=11,24-25(A) ; 9,7=22,9(C) ; 9,10=3,9 \\
(A) ; 10,4=21,22(A)\end{array}$ \\
\hline Gálatas & $6,7=22,8(A)$ \\
\hline Efésios & $5,18=23,31(A) ; 6,4=2,2(A), 3,11(A)$ \\
\hline Filipenses & $1,11=3,9(A), 11,30(A)$ \\
\hline Colossenses & $2,3=2,3 \mathrm{~s}(A)$ \\
\hline 1 Timóteo & $6,9=28,22(A)$ \\
\hline 2 Timóteo & $2,7=2,6(A) ; 4,14=24,12(A)$ \\
\hline Hebreus & $12,5=3,11 \mathrm{~s}(C) ; 12,7=13,24(A) ; 12,13=4,26(A)$ \\
\hline Tiago & $\begin{array}{l}1,3=27,21(A) ; 1,5=2,3-6(A) ; 1,19=15,1(A), 29,20(A) ; 2,6=14,21(A) ; \\
2,9=24,23(A) ; 2,13=19,17(A) ; 3,5=18,21(A) ; 3,6=16,27(A) ; 4,6=3,34 \\
(C) ; 4,14=27,1(A) ; 5,20=10,12(A)\end{array}$ \\
\hline 1 Pedro & $\begin{array}{l}1,7=17,3(A) ; 2,17=24,21(A) ; 3,6=3,25(A) ; 4,8=10,12 ; 4,18=11,31 \\
(C) ; 5,5=3,34(C)\end{array}$ \\
\hline 2 Pedro & $2,21=21,16(A) ; 2,22=26,11(A)$ \\
\hline 1 João & $1,8=20,9(A) ; 1,9=28,13(A) ; 2,16=27,20(A)$ \\
\hline Judas & $\mathrm{v} .12=25,14(A)$ \\
\hline Apocalipse & $3,14=8,22(A) ; 3,19=3,12(A) ; 9,11=15,11(A)$ \\
\hline
\end{tabular}

\subsection{Aspectos gerais}

Ao analisar o quadro apresentado, é possível identificar algumas características no uso de Provérbios pelos autores do NT:

1) A ausência de citações a Pr nas epístolas de 1 e $2 \mathrm{Ts}$, Tt, Fm, 2 e 3Jo. Observemos que Fm, 2 e 3Jo se justificam por serem, de fato, pequenas cartas sem um conteúdo mais apurado. No caso de 1Ts, é sabido que Paulo não faz nenhuma menção direta ao AT, e mesmo as menções indiretas estão mais relacionadas às crenças judaicas apocalípticas do que à tradição bíblica propriamente dita. Considerando que 2 Ts é um texto dêutero-paulino que tem forte dependência literária de $1 \mathrm{Ts}$, não é de admirar que a ausência permaneça. $\mathrm{O}$ caso mais curioso, talvez, seja o de Tt, que tem forte relação com as cartas a Timóteo e, ainda assim, não apresenta qualquer menção a Pr. Talvez seja um indício de uma independência autoral de Tt em relação a 1 e $2 \mathrm{Tm}$.

2) Pr é lembrando apenas uma vez em $\mathrm{Mc}, \mathrm{Gl}, \mathrm{Cl}, 1 \mathrm{Tm}, \mathrm{Jd}$. Destes, o caso que mais chama a atenção é de Mc, ao mesmo tempo em que se justifica. Mc é um texto de cunho rápido, algo feito no calor das emoções em função da 
revolta judaica contra Roma em 66 d.C., conforme a pesquisa tem indicado. ${ }^{19}$ Talvez por esse motivo, a produção do texto tenha privilegiado as memórias sobre Jesus, em vez de fazer arrazoados rabínicos sobre as Escrituras Hebraicas, como ocorre no material paulino e no Evangelho de Mateus. Ainda assim, desponta a alusão a $\operatorname{Pr} 28,24$ ("Quem rouba seu pai e sua mãe, e diz: 'Não é pecado!', é companheiro de bandido") na argumentação de Jesus sobre a pureza ritual, demonstrando a hipocrisia dos fariseus que deixavam de ajudar os pais para apresentar ofertas mais caras e assim aparentar maior espiritualidade. Também os demais casos são alusões, não havendo nenhuma citação direta. É de se considerar que $\mathrm{Gl}, \mathrm{Cl}, 1 \mathrm{Tm}$ e Jd estão em esferas diferentes de produção literária, ${ }^{20} \mathrm{o}$ que evidencia a presença de elementos sapienciais nas comunidades em diferentes partes e momentos cronológicos. Ou seja, ainda que de forma breve, Pr se faz presente em diferentes espaços.

3) Dos livros que mais utilizam Pr, Mt está em primeiro lugar, seguido de Tg, Lc, Rm e 2Cor. Não por coincidência, Mt e Tg são obras mais vinculadas ao pensamento judaico, enquanto Lc, Rm e 2Cor estão entre os escritos mais longos do NT, por isso se justifica a ampla presença. Pensando na relação entre as diversas citações, algumas em Lc estão em paralelo com Mt, enquanto a única citação de Mc é paralela de Mt. Há também paralelo de uso entre Mt e Jo e Mt e Rm. Mas em especial deve-se considerar a relação de Mt e Tg com Pr.

4) Considerando a forma numerada do livro, apenas Pr 5 não é citado nenhuma vez no NT.

Passaremos agora a analisar aspectos mais específicos, que podem nos ajudar a entender o processo de uso de Pr no NT. Para isso, analisaremos as citações diretas, em que o uso de Pr é inquestionável, os usos paralelos ou repetidos de alguns provérbios e os casos em que um texto do NT se apoia em mais de um provérbio simultaneamente.

\subsection{Citações diretas}

Numa contagem do quadro acima, dos 106 casos de intertextualidade entre Pr e o NT, a citação direta ocorre em apenas 9 textos: Mt 16,27; Rm 2,6; 3,15; 12,20; 2 Cor 9,7; Hb 12,5; Tg 4,6; 1Pd 4,18; 5,5. Ao observar o contexto no qual

${ }^{19}$ Em especial na obra de MYERS, C., O Evangelho de São Marcos; CARNEIRO, M., Os Evangelhos Sinóticos, p. 149.

${ }^{20}$ Consideramos aqui que Gl é uma epístola autêntica de Paulo, $\mathrm{Cl}$ é controversa quanto à autoria, 1 Tm é dêutero-paulina e Jd é parte de uma produção de outro círculo apostólico. 
eles são citados, percebe-se liberdade em alterar o sentido original, às vezes citando apenas um trecho ou enquadrando o provérbio em outro contexto. Em parte, isso se deve pelo fato dos provérbios serem compilados sem um contexto pré-definido, o que permite essa liberdade dos autores do NT.

Em Mt 16,27, ao falar do juízo, Jesus afirma que o Filho do Homem "retribuirá a cada um de acordo com o seu comportamento". Essa afirmação aparece em Pr 24,12, em sua parte final. O texto completo diz:

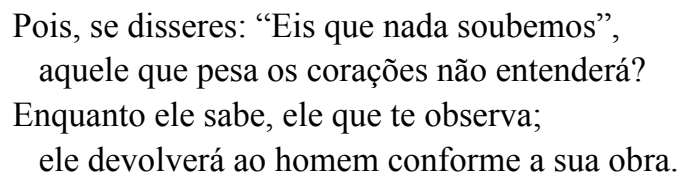

A aplicação do provérbio, que tinha como fundamento a vida humana, passa a ter um valor escatológico, visando o juízo sobre toda a humanidade. Neste caso, o mesmo provérbio é utilizado em Rm 2,6, pelo apóstolo Paulo, também num contexto escatológico. Isso indica que esse sentido era conhecido e utilizado, ao menos pelos cristãos.

Romanos tem uma citação emprestada; em 3,15 Paulo faz uma compilação de citações proféticas, dentre elas Is 59,7, cujo conteúdo é similar ao de $\operatorname{Pr}$ 1,16 . Num quadro podemos ver a semelhança entre os textos:

\begin{tabular}{|l|l|l|}
\hline Pr 1,16 & Rm 3,15 & Is 59,7 \\
\hline $\begin{array}{l}\text { Porque os pés deles correm } \\
\text { para o mal, apressam-se para } \\
\text { derramar sangue. }\end{array}$ & $\begin{array}{l}\text { Seus pés são velozes } \\
\text { para derramar sangue. }\end{array}$ & $\begin{array}{l}\text { Seus pés correm atrás do mal; } \\
\text { eles apressam-se a derramar } \\
\text { sangue inocente. }\end{array}$ \\
\hline
\end{tabular}

A comparação entre os três textos faz pensar, inclusive, na intertextualidade dentro do próprio cânon judaico. Neste caso, Paulo estaria pensando em qual texto: de Provérbios ou Isaías? No contexto de Rm, por compilar citações proféticas, é mais provável que ele tivesse em mente Isaías e não Provérbios. Para os estudiosos da crítica textual, a ausência deste verso em Pr nos manuscritos gregos mais antigos (alguns anteriores aos manuscritos de Qumran) sugere que Pr 1,16 seja uma glosa de Isaías no texto sapiencial. ${ }^{21}$ Por isso mencionamos essa citação como emprestada, posto que, mesmo estando em Provérbios, veio de Isaías.

${ }^{21}$ Ver a nota crítica deste versículo na Bíblia de Jerusalém, p. 1022. 
Há ainda uma terceira citação de Provérbios em Romanos, no caso em 12,20, citando Pr 25,21-22. Ali, Paulo organiza o trecho parenético da epístola, indicando a necessidade dos cristãos tratarem os inimigos com caridade. $\mathrm{O}$ texto de Pr diz:

Se o teu inimigo tem fome, dá-lhe de comer;

se tem sede, dá-lhe de beber:

Assim amontoas brasas sobre sua cabeça, e Iahweh te recompensará.

Na citação Paulo suprime o trecho final, não atrelando o ato de ajudar o inimigo com alguma recompensa. Para o apóstolo, a comunidade deve se engajar num comportamento diferente da sociedade, não porque será recompensada, mas porque é a vontade de Deus, ou ainda é o que se espera da comunidade que expressa a nova vida em Cristo ( $\mathrm{Rm} 12,1-2)$.

Ainda no corpus paulino, há um caso bastante peculiar, em 2Cor 9,7. Neste trecho, Paulo está tratando da necessidade de auxiliar as comunidades empobrecidas, por isso afirma, como que citando um provérbio: "Deus ama a quem dá com alegria". Aparentemente, encontramos a citação de $\operatorname{Pr} 22,8$. O provérbio hebraico, porém, está bem distante desta versão; ele nada fala a respeito de Deus ou do justo. É a versão grega da LXX que traz essa informação. O quadro abaixo demonstrará isso, juntando o v.9 na versão hebraica:

\begin{tabular}{|l|l|}
\hline Pr 22,8-9 versão hebraica & Pr 22,8 versão grega LXX (tradução nossa) \\
\hline $\begin{array}{l}\text { Quem semeia a injustiça colherá a desgraça, } \\
\text { e a vara de sua cólera o ferirá. }\end{array}$ & $\begin{array}{l}\text { O que semeia maldade colherá males e } \\
\text { calamidades, } \\
\text { e completará suas obras, } \\
\text { porque dá de seu pão ao fraco. } \\
\text { Deus abençoa ao homem que dá com } \\
\text { alegria, não por vaidade, } \\
\text { ele completará suas obras. }\end{array}$ \\
\hline
\end{tabular}

O trecho em itálico da versão grega apresenta a mesma ideia presente em 2Cor 9,7, de que Deus abençoa, no caso da LXX, ou ama, no caso de Paulo, à pessoa que doa com alegria. $O$ verso 9 da versão hebraica se aproxima desta ideia. Curioso é o fato de que o v.9 da versão grega repete a ideia sem inserir a figura de Deus. ${ }^{22}$ Ao citar o trecho em questão, Paulo demonstra familiaridade

${ }^{22}$ Percebe-se, neste caso, como a tradução da Septuaginta é em si mesma uma hermenêutica da tradição hebraica. Mas não iremos aprofundar a questão, pois não se trata do escopo deste artigo. 
com a versão grega, a ponto de utilizar com certa adaptação. Neste caso, fica clara a liberdade do apóstolo com o texto fonte.

Saindo do campo de escritos paulinos encontramos uma citação em Hb 12,56, fazendo clara indicação de que a comunidade conhecia a exortação contida em Pr 3,11-12, com algumas alterações, como se pode perceber na comparação:

\begin{tabular}{|c|c|}
\hline Pr 3,11-12 & $\mathrm{Hb} 12,5-6$ \\
\hline $\begin{array}{l}\text { Meu Filho, não desprezes a disciplina de } \\
\text { Iahweh, } \\
\text { nem te canses com a sua exortação; } \\
\text { porque Iahweh repreende os que ele ama, } \\
\text { como um pai ao filho que preza. }\end{array}$ & $\begin{array}{l}\text { Meu filho, não desprezes a correção do Senhor, } \\
\text { não desanimes quando ele te repreende; } \\
\text { pois o Senhor educa a quem ama, } \\
\text { e castiga a quem acolhe como filho. }\end{array}$ \\
\hline
\end{tabular}

As diferenças nos textos podem estar relacionadas à versão grega de Provérbios, pois o texto de $\mathrm{Hb}$ segue ipsis litteris o texto grego. Outro caso em que o autor do NT tem em mente não a versão hebraica, mas grega, do provérbio.

Depois, em Tg 4,6, encontramos outro caso similar ao de Hebreus: ao citar Pr 3,34 ele se apoia na versão grega, e não na versão hebraica, pela diferença no texto em relação a esta - a versão em grego também é idêntica nos dois casos.

\begin{tabular}{|l|l|}
\hline $\operatorname{Pr} 3,34$ versão hebraica & $\operatorname{Tg} 4,6$ \\
\hline $\begin{array}{c}\text { Ele zomba dos zombadores insolentes, } \\
\text { mas aos pobres concede o seu favor. }\end{array}$ & $\begin{array}{c}\text { Deus resiste aos soberbos, } \\
\text { mas dá graça aos humildes. }\end{array}$ \\
\hline
\end{tabular}

Este provérbio também é citado em 1Pd 5,5 e, de novo, ele segue as exatas palavras da LXX, em vez de traduzir a versão hebraica. Isso pode nos levar a fazer algumas considerações a respeito da versão dos Provérbios que as comunidades cristãs tinham em mãos.

Antes, porém, vale indicar outra citação de Provérbios presente em 1Pd. Em 4,18 o autor cita Pr 11,31, referindo-se ao juízo escatológico do povo de Deus. Seguindo o padrão que percebemos acima, também neste caso o autor se apoia na versão grega para sua citação, cujas palavras são idênticas. Comparando com a versão hebraica percebemos a diferença:

\footnotetext{
${ }^{23}$ A versão deste trecho pela tradução João Ferreira de Almeida, Revista e Atualizada, acaba se aproximando da versão grega. Ela afirma: "Certamente, ele escarnece dos escarnecedores, mas dá graça aos humildes". Provavelmente isso ocorre para aproximar as versões de Provérbios e Tiago.
} 


\begin{tabular}{|l|l|}
\hline Pr 11,31 & $1 \mathrm{Pd} 4,18$ \\
\hline $\begin{array}{c}\text { Se o justo aqui na terra recebe seu salário, } \\
\text { quanto mais o ímpio e o pecador! }\end{array}$ & $\begin{array}{c}\text { Se o justo com dificuldade consegue salvar-se, } \\
\text { em que situação ficará o ímpio e o pecador? }\end{array}$ \\
\hline
\end{tabular}

Ao analisar as diferentes citações de Provérbios feitas no NT, percebemos alguns aspectos comuns: tanto podiam citar o texto por memória oral, a partir da versão judaica, quanto temos casos em que a citação do NT se apoia na versão grega da LXX. Nestes casos, fica bastante claro pela exatidão das palavras em grego em ambos os textos comparados. Não deve nos admirar que isso ocorra, tendo em vista que a liturgia judaica no século I d.C. tinha a Septuaginta como base, tanto quanto a versão hebraica. Os judeus da Diáspora, bem como diversos grupos dentro da Palestina, liam mais o grego do que o hebraico, por isso a familiaridade com essa versão. ${ }^{24}$ Considerando que, para eles, a versão hebraica ainda não tinha prevalência sobre a grega, não é de surpreender tal escolha.

\subsection{Os casos de alusões de Provérbios}

Chegamos a um ponto em que fica mais complexo analisar caso a caso e verificar o uso em si, posto que, nas alusões, o que está em jogo é a ideia do texto original e não as palavras. Daí, uma maior liberdade no uso das fontes e dificuldade de comparar. Queremos destacar aqui não a comparação de cada texto, mas um determinado uso comum pelos autores, indicando tendências do uso de Provérbios. Para isso, iremos separar a análise em dois grupos: no primeiro, falaremos de provérbios utilizados por mais de um autor; depois, sobre textos que se apoiam em mais de um provérbio.

\section{Uso comum de um provérbio por mais de um autor}

Há alguns provérbios que deviam ser repetidos em diversas ocasiões, motivo pelo qual são lembrados por mais de um autor do NT. Em dois casos,

\footnotetext{
${ }^{24}$ É importante considerar a afirmação de Helmut Koester: "A tradução [da Septuaginta] baseouse na forma alexandrina do texto hebraico, um ramo do texto palestino da Bíblia. Em muitas passagens onde a Septuaginta difere da tradição babilônica da Bíblia Hebraica (preservada no texto massorético), as diferenças surgem do uso feito pelos tradutores desse texto hebraico palestino". KOESTER, H., Introdução ao Novo Testamento, p. 250. Para aprofundar a questão sobre a Septuaginta, ver SOARES, E., Septuaginta, 2009.
} 
trata-se de citações diretas: nos já comentados Pr 24,12, citado por Mt 16,27 e Rm 2,6, e no caso de Pr 3,34, citado na versão grega por Tg 4,6 e 1Pd 5,5. Nos demais casos é feita realmente a alusão, que estamos analisando.

Abaixo, um quadro comparativo do texto do provérbio original e da versão que os textos do NT apresentam:

\begin{tabular}{|l|l|l|}
\hline $\operatorname{Pr} 8,17$ & Mt 7,7 // Lc 11,9 & Jo 14,23ab \\
\hline $\begin{array}{c}\text { Eu amo os que me amam, } \\
\text { e os que madrugam por mim } \\
\text { hão de me encontrar. }\end{array}$ & $\begin{array}{c}\text { Pedi e vos será dado; } \\
\text { buscai e vos será aberto; }\end{array}$ & $\begin{array}{c}\text { Se alguém me ama, } \\
\text { guardará a minha palavra... }\end{array}$ \\
\hline
\end{tabular}

Neste caso, percebe-se a relação entre buscar e encontrar na tradição sinótica de Mt e Lc, e amar a sabedoria/Deus na tradição joanina. Duas formas diferentes de apreender o mesmo provérbio.

\begin{tabular}{|c|c|c|}
\hline $\operatorname{Pr} 9,9$ & Mt 13,12 & Lc 8,18 (paralelo de Mt) \\
\hline $\begin{array}{l}\text { Dá ao sábio, e ele se tornará } \\
\text { mais sábio, } \\
\text { Ensina o justo, e ele } \\
\text { aprenderá ainda mais. }\end{array}$ & $\begin{array}{l}\text { Pois àquele que tem, lhe } \\
\text { será dado e lhe será dado em } \\
\text { abundância, mas ao que não } \\
\text { tem, mesmo o que tem lhe } \\
\text { será tirado. }\end{array}$ & $\begin{array}{l}\text { Cuidai, portanto, do modo } \\
\text { que ouvis! Pois ao que tem, } \\
\text { será dado; e ao que não tem, } \\
\text { mesmo o que pensa ter, lhe } \\
\text { será tirado. }\end{array}$ \\
\hline
\end{tabular}

Jesus adapta o provérbio, estabelecendo uma relação entre ter e receber mais, e não ter e perder tudo, a partir da ideia do provérbio sobre o sábio. Era uma tônica de Jesus chamar a atenção dos ouvintes como um mestre sapiencial. ${ }^{25}$ Essa tradição foi aproveitada por Mateus e Lucas em suas versões do evangelho.

\footnotetext{
${ }^{25}$ MULLINS, T. Y., Jewish Wisdom Literature in the New Testament, p. 336. Para o autor, o Jesus histórico deve ser considerado como um sábio em Israel, antes de Messias. Ele afirma, num artigo de 1949: "Jesus, then, used Wisdom techniques (proverbs and parables) when he taught. He taught what the sages had taught. And he taught in the manner of a sage. Perhaps we have been blinded by the popular theology of western orthodoxy with its emphasis on Christ as Prophet, Priest, and King; certainly Jesus as a sage has been underemphasized. If this aspect of his life had received proper attention, we would have realized that here is material antedating the Gospel accounts" (Jesus, então, usou técnicas sapienciais (provérbios e parábolas) quando ele ensinava. Ele ensinava o que os sábios tinham ensinado. E ele ensinava da maneira de um sábio. Talvez tenhamos sido cegados pela ortodoxia da teologia popular ocidental com sua ênfase no Cristo como profeta, sacerdote e rei; certamente Jesus como um sábio foi subestimado. Se esse aspecto de sua vida tivesse recebido a devida atenção, teríamos percebido que aqui temos material anterior ao que consta nos Evangelhos.), p. 337. Oportunamente, trabalharemos o tema em outro artigo.
} 


\begin{tabular}{|l|l|l|}
\hline $\operatorname{Pr} 14,21$ & Mt 5,7 & Tg 2,6 \\
\hline \begin{tabular}{l} 
Aquele que despreza o próximo peca; $\begin{array}{l}\text { feliz é quem tem piedade } \\
\text { dos pobres. }\end{array}$ \\
\hline
\end{tabular} & $\begin{array}{l}\text { Felizes os misericordiosos, } \\
\text { porque alcançarão } \\
\text { misericórdia. }\end{array}$ & $\begin{array}{l}\text { E, no entanto, vós } \\
\text { desprezais o pobre!... }\end{array}$ \\
\hline
\end{tabular}

A relação de Mt com o provérbio está na ideia de ser misericordioso para com os pobres. No contexto das bem-aventuranças, em que felizes são os pobres, porque o reino pertence a eles, a ideia de que a misericórdia está relacionada a eles é bastante apropriada. Isso nos leva a uma chave de leitura de Mt 5,3-10. Em Tiago essa relação fica mais clara ainda, posto que no contexto ele está criticando a atitude da comunidade em fazer acepção de pessoas, como se fossem ricos, coisa que de fato não eram. Na perícope onde está $\operatorname{Tg}$ 2,6 há ainda outra alusão a um provérbio sobre parcialidade no juízo: $\operatorname{Tg}$ 2,9 se refere a Pr 24,23, que diz: "Não é bom ser parcial no julgamento". Vale ressaltar que, neste caso, também há uma referência a Pr 17,5: "Quem zomba do pobre ultraja seu Criador, quem ri do infeliz não ficará impune". Esse fato ocorre em outros casos, como será visto a seguir.

\begin{tabular}{|l|l|l|}
\hline Pr 19,17 & Mt 25,40 & Tg 2,13 \\
\hline Quem faz caridade ao & Ao que lhe responderá o rei: & Porque o julgamento será \\
pobre empresta a Iahweh, & "Em verdade vos digo: cada & sem misericórdia para quem \\
e ele dará a sua & vez que o fizeste a um desses & não pratica a misericórdia. \\
recompensa. & meus irmãos mais pequeninos, & A misericórdia desdenha o \\
& a mim o fizestes". & julgamento. \\
\hline
\end{tabular}

Ainda na temática do pobre, temos duas alusões a um provérbio que foi inculcado na cultura brasileira. ${ }^{26}$ No caso de Mateus, a relação é bem direta, quando o Senhor afirma que, ao estender a mão aos necessitados, a pessoa está, na verdade, servindo ao próprio Senhor. Daí a ideia da recompensa. Já em Tiago a alusão é mais distante, porém, no contexto da perícope (2,1-13), bastante relacionada.

\begin{tabular}{|l|l|l|}
\hline Pr 25,21 & Mt 5,44 & Lc 6,27 \\
\hline $\begin{array}{l}\text { Se o teu inimigo tem fome, } \\
\text { dá-lhe de comer; } \\
\text { se tem sede, dá-lhe de beber. }\end{array}$ & $\begin{array}{l}\text { Eu, porém, vos digo: amai } \\
\text { os vossos inimigos e orai } \\
\text { pelos que vos perseguem; }\end{array}$ & $\begin{array}{l}\text { Eu, porém, vos digo, a vós que } \\
\text { me escutais: Amai os vossos } \\
\text { inimigos, fazei o bem aos que } \\
\text { vos odeiam. }\end{array}$ \\
\hline
\end{tabular}

${ }^{26}$ Comumente se diz no Brasil: "Quem dá aos pobres, empresta a Deus". 
O provérbio sobre como tratar o inimigo foi citado por Paulo em $\mathrm{Rm}$ 12,20, como já indicado. Mas também é usado por Jesus para estabelecer a forma de tratar os inimigos, fazendo o bem em vez do mal. A dupla tradição de Mt e Lc registra essa afirmação do mestre. Aqui também há um segundo provérbio que pode ser considerado como inspiração, no caso, Pr 24,17: "se teu inimigo cai, não te alegres, e teu coração não exulte se ele tropeça".

\begin{tabular}{|l|l|l|}
\hline Pr 27,1 & Mt 6,11// Lc 11,3 & Tg 4,14 \\
\hline $\begin{array}{l}\text { Não te felicites pelo dia de amanhã, } \\
\text { pois não sabes o que o hoje gerará. }\end{array}$ & $\begin{array}{l}\text { O pão nosso de cada } \\
\text { dia dá-nos hoje. }\end{array}$ & $\begin{array}{l}\text { E, no entanto, não sabeis } \\
\text { nem mesmo o que será da } \\
\text { vossa vida amanhã. }\end{array}$ \\
\hline
\end{tabular}

Ao falar sobre a nulidade de pré-estabelecer o futuro, o provérbio foi base para dois textos diferentes, porém, com fundo comum. Na tradição de Jesus, registrada duplamente por $\mathrm{Mt}$ e Lc, aparece como parte da oração conhecida como Pai-Nosso. Nela, há uma solicitação do cuidado diário de Deus, tendo o hoje como base e não o amanhã. Já em Tiago, a alusão é mais clara; o apóstolo trata sobre os planos que são feitos sem considerar a fragilidade da vida. Para ele, é preciso sempre afirmar: "Se o Senhor quiser, estaremos vivos e faremos isto ou aquilo". Essa verdade também foi bastante introjetada em nossa cultura. ${ }^{27}$ No caso desta afirmação, há outro provérbio que fundamenta a mesma ideia: $\operatorname{Pr} 3,28:$ "Não digas ao teu próximo: 'Vai embora! Passa depois! Amanhã dar-te-ei...' E tens a coisa na mão".

\begin{tabular}{|l|l|l|}
\hline Pr 28,24 & Mt 15,5 & Mc 7,11 \\
\hline $\begin{array}{l}\text { Quem rouba seu pai e sua } \\
\text { mãe, e diz: "Não é pecado!”, } \\
\text { é companheiro de bandido. }\end{array}$ & $\begin{array}{l}\text { Vós, porém, dizeis: } \\
\text { Aquele que disser ao pai } \\
\text { ou à mãe: “Aquilo que de } \\
\text { mim poderias receber foi } \\
\text { consagrado a Deus”, }\end{array}$ & $\begin{array}{l}\text { Vós, porém, dizeis: Se alguém } \\
\text { disser a seu pai ou à sua mãe: } \\
\text { os bens que eu poderia te } \\
\text { ajudar são Corban, isto é, } \\
\text { oferta sagrada... }\end{array}$ \\
\hline
\end{tabular}

Aqui retomamos um provérbio citado acima, no contexto de Marcos. Aparentemente, essa memória sobre a pureza foi incorporada por Mateus, numa versão mais curta do mesmo episódio, mas trazendo também a alusão ao provérbio.

\footnotetext{
${ }^{27} \mathrm{Na}$ sabedoria popular, até pouco tempo era costume ouvir dizer: "Se Deus quiser, faremos isto...".
} 
De forma inversa, existem casos em que um texto faz alusão a mais de um provérbio. Talvez nem mesmo o autor tivesse consciência disso, pois os provérbios podem ser similares. Predominantemente isso ocorre no Evangelho de Mateus, em especial no bloco conhecido como Sermão do Monte. Também ocorre tal situação em At, Rm e Tg, mas apenas uma vez em cada livro. É importante lembrar, mais uma vez, que a alusão está mais para a interdiscursividade que para a intertextualidade, pois o que está em jogo não são as palavras em si, mas a ideia geral da fonte.

Vimos acima alguns casos em que o dito de Jesus se fundamenta em mais de um provérbio. Veremos outros casos, sempre no Evangelho de Mateus. Em Mt 5,39, quando Jesus manda o discípulo oferecer a outra face contra quem lhe bater, há referência a $\operatorname{Pr} 20,22$ e 24,29:

\begin{tabular}{|c|c|c|}
\hline Mt 5,39 & $\operatorname{Pr} 20,22$ & $\operatorname{Pr} 24,29$ \\
\hline $\begin{array}{l}\text { Eu, porém, vos digo: não } \\
\text { resistais ao homem mau; } \\
\text { antes, àquele que te fere } \\
\text { na face direita oferece-lhe } \\
\text { também a esquerda. }\end{array}$ & $\begin{array}{l}\text { Não digas: vingar-me-ei do } \\
\text { mal; } \\
\text { espera por Iahweh e ele te } \\
\text { salvará. }\end{array}$ & $\begin{array}{l}\text { Não digas: "Segundo me } \\
\text { fez, assim lhe farei! } \\
\text { Devolverei a cada um } \\
\text { conforme a sua obra!" }\end{array}$ \\
\hline
\end{tabular}

$\mathrm{Na}$ passagem em que Jesus confronta os fariseus sobre comer com pecadores, por trás de sua afirmação sobre misericórdia, além da óbvia citação de Os 6,6, também há no horizonte dois provérbios: Pr 16,7 e 21,3:

\begin{tabular}{|l|l|l|}
\hline Mt 9,13 & Pr 16,7 & Pr 21,3 \\
\hline $\begin{array}{l}\text { Ide, pois, e aprendei o que } \\
\text { significa: Misericórdia } \\
\text { quero e não o sacrificio. } \\
\begin{array}{l}\text { Com efeito, não vim chamar } \\
\text { justos, mas pecadores. }\end{array}\end{array}$ & $\begin{array}{l}\text { Quando Iahweh aprova os } \\
\text { caminhos de um homem, } \\
\text { ele o reconcilia até com seus } \\
\text { inimigos. }\end{array}$ & $\begin{array}{l}\text { Praticar a justiça e o direito, } \\
\text { vale mais para Iahweh que } \\
\text { os sacrifícios. }\end{array}$ \\
\hline
\end{tabular}

Ao final da parábola da pérola (Mt 13,44-46), Jesus faz uma afirmação que tem como fundo temático os provérbios de 3,15 e 8,11 : 


\begin{tabular}{|l|l|l|}
\hline Mt 13,46 & $\operatorname{Pr} 3,15$ & $\operatorname{Pr} 8,11$ \\
\hline $\begin{array}{l}\text { Ao achar uma pérola de } \\
\text { grande valor, vai, vende tudo } \\
\text { o que possui e a compra. }\end{array}$ & $\begin{array}{c}\text { [A sabedoria] É mais } \\
\text { valiosa do que as pérolas; } \\
\text { nada que desejas a iguala. }\end{array}$ & $\begin{array}{l}\text { Porque a Sabedoria é melhor } \\
\text { que as pérolas, } \\
\text { e nenhuma joia lhe é } \\
\text { comparável! }\end{array}$ \\
\hline
\end{tabular}

Em Mt 21,32, Jesus se refere a João Batista como aquele que andou no caminho de justiça. Essa expressão pode ser encontrada em $\operatorname{Pr} 8,20,12,28$ e 21,21. Citamos aqui o primeiro texto: "Eu [a sabedoria] caminho pela senda da justiça e ando pelas veredas do direito".

No caso de At 24,5, a referência é curiosa. O texto fala da acusação dos judeus contra Paulo diante de Félix, procurador da Judeia. Ao citar o apóstolo como um homem que "suscita conflitos entre os judeus do mundo inteiro", Tertulo, o acusador, está tendo em mente dois provérbios, que falam de pessoas causadoras de contendas:

Expulsa o zombador, e a querela cessará; cessarão as demandas e o menosprezo. $(\operatorname{Pr} 22,10)$

Os zombadores alvoroçam a cidade; mas os Sábios contêm a ira. (Pr 29,8)

Desse modo, parece que Tertulo se vê como sábio que deseja evitar o conflito causado pelo zombador Paulo. O apóstolo, em sua epístola aos Romanos, ao falar sobre a vingança, segue o mesmo raciocínio de Jesus, tendo como base uma combinação entre Pr 20,22 e 3,4: "A ninguém pagueis o mal com o mal; seja a vossa preocupação fazer o que é bom para todos os homens...".

Finalmente, Tiago, tratando da prudência da língua (1,16-27), tem como horizonte dois provérbios muito importantes a respeito da palavra:

\begin{tabular}{|l|l|l|}
\hline $\operatorname{Tg} 1,19$ & Pr 15,1 & $\operatorname{Pr} 29,20$ \\
\hline $\begin{array}{l}\text { Isso podeis saber com certeza, meus } \\
\text { amados irmãos. Que cada um esteja } \\
\text { pronto para ouvir, mas lento para falar e } \\
\text { lento para encolerizar-se. }\end{array}$ & $\begin{array}{l}\text { Resposta branda } \\
\text { aplaca a ira, } \\
\text { palavra ferina atiça a a } \\
\text { cólera. }\end{array}$ & $\begin{array}{l}\text { Vês um homem } \\
\text { precipitado no falar? } \\
\text { Espera-se mais do } \\
\text { insensato do que dele. }\end{array}$ \\
\hline
\end{tabular}




\section{Conclusão}

Ao pesquisar o uso do Livro de Provérbios pelos autores do Novo Testamento, podemos considerar os seguintes aspectos: primeiro, fica bem claro que, para os cristãos primitivos, Provérbios fazia parte de sua memória e provavelmente era utilizado cotidianamente, reproduzindo o processo da formação do livro. Segundo, que havia uma liberdade por parte dos autores do Novo Testamento no uso dos provérbios, não se obrigando a citar ipsis litteris o provérbio no qual se baseavam, a não ser em alguns casos, como foi demonstrado. No geral, predomina mais o uso da alusão do que da citação, inclusive no material da tradição de Jesus.

A forma como Jesus utilizou Provérbios não foi devidamente analisada no artigo, mas é importante perceber o quanto ele estava vinculado à tradição sapiencial; a maior parte do material analisado vem de ditos da ipsissima vox Iesu, em especial no Evangelho de Mateus. Por isso, não é de se admirar que o método utilizado por ele tenha se popularizado entre os seus seguidores. Como exemplo podemos pegar a epístola de Tiago, que segue uma tradição de ditos similar, e apresenta muitas correlações com Mateus no uso de Provérbios, sugerindo uma relação com a tradição dos ditos jesuânicos.

A partir do que foi levantado e indicado aqui, pode-se aprofundar a reflexão, procurando pensar o quanto os cristãos se fundamentavam na Bíblia Hebraica, ou ainda, na Septuaginta, mas ainda não a consideravam canônica no nível de evitar alterar o texto citado, sacralizando a letra. Para eles, vale mais a mensagem sapiencial, sua proposição para a vida e espiritualidade. Por isso, pode-se falar numa espiritualidade sapiencial, a partir, inclusive, do próprio Jesus, assunto que abre possibilidade para novas reflexões e pesquisas.

\section{Referências bibliográficas}

BARRERA, J. T. A Bíblia Judaica e a Bíblia Cristã. Introdução à história da Bíblia. Petrópolis: Editora Vozes, 1996.

BÍBLIA de Jerusalém. Nova ed. rev. e ampl. 11. reimp. São Paulo: Paulus, 2016. CARNEIRO, M. S. Jesus, a Torá e os Nebîim, e o pleno cumprimento da justiça em Mt 5,17-20. Atualidade Teológica, v. 13, n. 32, p. 278-291, mai./ago. 
2009. Disponível em: <https://www.maxwell.vrac.puc-rio.br/18326/18326. PDFXXvmi=>. Acesso em: 01 mar. 2020.

CARNEIRO, M. Os Evangelhos Sinóticos. Origens, memória e identidade. São Paulo: Fonte Editorial, 2016.

ELLIS, D. J., O uso neotestamentário do Antigo Testamento. In: BRUCE, F. F. (Org.). Comentário Bíblico NVI. Antigo e Novo Testamentos. São Paulo: Editora Vida, 2009. p. 1540-1543.

HABTU, T. Introdução à Literatura Sapiencial. In: ADEYEMO, T. (Ed.). Comentário Bíblico Africano. São Paulo: Editora Mundo Cristão, 2010. p. 1517-1520.

JEREMIAS, J. Teologia do Novo Testamento. Nova edição revista e atualizada. São Paulo: Teológica / Paulus, 2004.

KOESTER, H. Introdução ao Novo Testamento. São Paulo: Paulus, 2005. v.1.

LENHARDT, P.; COLLIN, M. A Torah oral dos fariseus: textos da tradição de Israel. São Paulo: Paulus, 1997

MELGARES, J. Uso del Antiguo Testamento en el Nuevo: Asuntos Generales. Kairós, v. 45, p. 41-66, jul./dez. 2009.

MYERS, C. O Evangelho de São Marcos. São Paulo: Paulinas, 1992.

MULLINS, T. Y. Jewish Wisdom Literature in the New Testament. Journal of Biblical Literature, v. 68, n. 4, p. 335-339, dez. 1949.

NESTLE, E.; ALAND, K. Novum Testamentum Graece. Edição com margens. Introdução em português. 28. ed. rev. Münster/Westphalia: Deutsche Bibel Gesellschaft / Sociedade Bíblica do Brasil, 2012.

NOGUEIRA, P. A. S. Hermenêutica da Recepção: textos bíblicos nas fronteiras da cultura e no longo tempo. Estudos da Religião, v. 26, n. 42, p. 15-31, jan./ jun. 2012.

SAMOYAULT, T. A Intertextualidade. São Paulo: Aderaldo \& Rothschild, 2008.

SCARDELAI, D., VILLAC, S. Introdução ao Primeiro Testamento. Deus e Israel constroem a história. São Paulo: Paulus, 2007.

SCHWIENHORST-SCHÖNBERGER, L. O Livro de Provérbios. In: 
ZENGER, E. et. al. Introdução ao Antigo Testamento. São Paulo: Edições Loyola, 2003. p. 323-331.

SKA, J. L. O Antigo Testamento. Explicado aos que conhecem pouco ou nada a respeito dele. São Paulo: Paulus, 2015.

SOARES, E. Septuaginta. Guia Histórico e Literário. São Paulo: Hagnos, 2009.

STORY, C. I. K. The Book of Proverbs and Northwest Semitic Literature. Journal of Biblical Literature, v. 64, n. 3, p. 319-337, set. 1945.

\section{Marcelo da Silva Carneiro}

Doutor em Ciências da Religião pela Universidade Metodista de São Paulo Docente de Teologia na Faculdade da Igreja Presbiterana Independente São Paulo / SP - Brasil E-mail: professor.carneiro@hotmail.com

Recebido em: 09/01/20

Aprovado em: 27/04/20 